on the problem of the essence of criterion assessment, to build an algorithm for assessing the effectiveness of project activities and to study the level of effectiveness of project activities using a parametricindicative evaluation model. In particular, the analysis of the conceptual apparatus associated with the project evaluation proves that the main deadlines are clearly spelled out and do not require an additional clarification. Also, we analyzed the concepts of project activity, assessment, criteria, algorithms and procedures. The assessment is analyzed as a process of comparing the goal and the result. Noted to the fact that the project evaluation is both an integral part of the process of their implementation and at the same time can be a separate procedure for determining their efficacy.

Right competent definition of the evaluation criteria, the use of their adequate measures is the key to the correct evaluation of any project. Based on the analysis of scientific sources it has been determined that the most effective assessment is using the criterion apparatus. In addition, it was noted that the criteria can replace the goals of the project and can also serve as indicators of his quality. Also, standards, measures, goals can be used as criteria. Factors affecting the project activity evaluation technique are highlighted.

The proposed algorithm for concluding criteria for evaluating project activities was applied in the framework of an experimental study. To assess the qualitative characteristic, a way to determine the degree of intensity of the object's expression is sought. A parametric-exponential assessment model was proposed in which the indicators of the second row are placed in a gradation order. For example, it shows the results of the assessment of the parameter of project activity "Participation of students in project activities". A promising area of work in the future may be the substantiation of criteria for evaluating international projects.

Key words: project activity, assessment, assessment criteria, gradation, assessment, parametricexponential model.

Дата надходження статті: 30.10.2020 p.

Рецензент: доктор педагогічних наук, доцент Боднар О. С.

У, ДК 372.851

DOI https://doi.org/10.37915/pa.vi46.108

Кузьмич В. I., orcid.org/0000-0002-8150-3456

Кузьмич А. В.,

orcid.org/0000-0002-6727-9064

\title{
ФОРМУВАННЯ ПОНЯТТЯ КУТА У ШКІЯЬНОМУ КУРСІ МАТЕМАТИКИ ЗАСОБАМИ МЕТРИЧНОЇ ГЕОМЕТРІї
}

У шкільному курсі математики кут систематично розпочинають вивчати з п'ятого класу. Це поняття, як не дивно, до цзвого часу не мае сталого означення, чи хоча б опису. Навіть у вищій математиці воно трактуеться по-різному, не говорячи вже про шкільні підручники. Кут сприймають $i$ як лінію, $i$ як частину площцини, а інколи ототожнюють кут із його числовою характеристикою. Таке сприйняття кута, на нашу думку, спричинене широким його застосуванням у різноманітних галузях науки і техніки.

У даній роботі пропонуеться означення кута як упорядкованої трійки точок. Таке означення, на нашу думку, є логічним доповненням існуючих означень кута. Крім того, такий підхід до поняття кута дає можливість використати елементи метричної геометрії для вивчення його властивостей, а також використати кут для означення поняття прямолінійного розміщення точок. Застосування основних понять метричної геометрії до вивчення

\section{(C) Кузвмич В. I.}


властивостей кута уможливлюе ознайомлення учнів з елементами неевклідових геометрій, яке, на даний момент, повністю відсутне у шкільних підручниках з геометрії, включно з підручниками для класів з поглибленим вивченням математики.

Введення узагальненого поняття кута у шкільний курс геометрії, на наш погляд, слід розпочинати з демонстрації прикладів, щзо вказують на відносність основних геометричних понять - точка, прямолінійність, відстань, кут. Такі приклади підготують учнів до адекватного сприйняття у подальшому основних понять $і$ співвідношень неевклідових геометрій. Використання для ичього метричної геометрії позбавляе необхідності розглядати значну кількість аксіом, оскільки при изьому використовуються лище три аксіоми відстані, які інтуїтивно зрозумілі учням.

У роботі наведено ряд прикладів, які можуть розглядатися на уроках у класах iз поглибленим вивченням математики, а також у позаурочний час на заняттях математичного гуртка або жн на факультативах із математики.

Ключові слова: поглиблене вивчення математики, точка, кут, відстань, простір, метрика, метрична геометрія, неевклідова геометрія.

Постановка проблеми. Питання, що розглядаються у даній роботі, зорієнтовані, в основному, на матеріал з математики, що пропонуеться здобувачам середньої освіти на базовому та профільному рівнях. Зокрема, більшість матеріалу стосується навчання математики у класах із поглибленим ії вивченням.

Сучасний стан математичної освіти ставить питання про необхідність ознайомлення учнів, які навчаються у класах із поглибленим вивченням математики, 3 основними поняттями та фактами неевклідових геометрій. Зробити це, безпосередньо звертаючись до фактичного матеріалу таких геометрій, досить складно, зважаючи на значний рівень його формалізації. Для вирішення цього питання автори пропонують використати засоби метричної геометрії як найбільш наближеної до шкільного курсу геометрії. Пропонується розпочати цю роботу з формування узагальнених основних геометричних понять та об'єктів, таких як: точка, кут, прямолінійне розміщення точок.

Аналіз досліджень. Вивчення основних елементів неевклідових геометрій (зокрема, сферичної геометрії) розглядалась рядом авторів. Так, наприклад, I. Ленарт [12] вивчав співвідношення між поняттями «точка» і «пряма» у різних видах геометрій - сферичній, гіперболічній та плоскій - шляхом побудови відповідної алгебраїчної системи (порівняльна геометрія). У роботі I. Денарта i А. Рибак [13] описано підхід до використання порівняльної геометрії у шкільному курсі математики у парадигмі реформування математичної освіти в Угорщині. Вплив вивчення неевкдідових геометрій на формування професіоналізму вчителя математики розглядався у роботі Н. Бурової [1].

Мета статті: проаналізувати найбільш ефективні шляхи формування поняття «кут» у шкільному курсі математики засобами метричної геометрії.

Виклад основного матеріалу. У «Началах» Евкліда сформульовано таку дефініцію: «Плоский кут є нахия одна до одної двох діній, що зустрічаються у пдощині одна з одною, але які не розміщені по (одній) прямій» [9, с. 11-12].

У чинних підручниках 3 математики при визначенні кута притримуються геометричної системи Д. Гільберта, який пише: «Нехай $\alpha$ є довільна площина, a h, k - якінебудь два різні промені у площині $\alpha$, що виходять 3 точки $\mathrm{C}$ і належать різним прямим. Систему цих двох променів $\mathrm{h}, \mathrm{k}$ ми називаємо кутом $\mathrm{i}$ позначаємо $\angle(\mathrm{h}, \mathrm{k})$ або $\angle(\mathrm{k}, \mathrm{h}) »[2, \mathrm{c} .10]$.

Наприклад, у п'ятому класі поняття кута подають як сукупність двох променів зі спільним початком.

Зокрема, А. Мерздяк, В. Полонський, М. Якір у підручнику з математики для закладів загадьної середньої освіти пропонують дати учням таке пояснення: «Проведемо на аркуші паперу два промені ВА та ВС із спільним початком у точці В (рис. 71). 


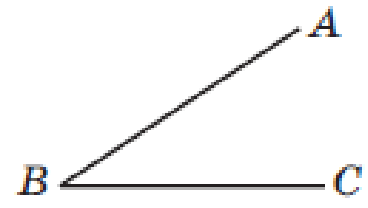

Рис. 71

Фігуру, утворену двома променями, які мають спільний початок, називають кутом» $[5$, с. 69].

При цьому автори наголошують, що у записі кута важдивий порядок слідування букв: «Буква, яка відповідає вершині, має бути другою з трьох букв» [там само].

Треба відзначити, що на рисунку кута самі точки А, В і С не зображені, хоча і передбачаються. Це наслідок характерної для поняття кута неоднозначності його тлумачень. Наприклад, у сьомому класі кут уже інтерпретують як частину площини, обмежену двома променями зі спільним початком.

Наведемо фрагмент навчального посібника вищезгаданих авторів, який доцільно використовувати при вивченні геометрії в сьомому класі: «На рисунку 3.4, а зображено фігуру, яка складається $з$ двох променів ОА та ОВ, що мають спільний початок.

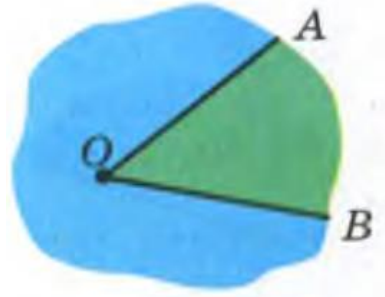

$a$

Pис. 3.4

Ця фігура ділить площину на дві частини, які виділено різними кольорами. Кожну із цих частин разом із променями ОА та ОВ називають кутом» [6, с. 23].

Кожне із наведених вище понять кута, на наш погдяд, може використовуватись узалежності від конкретних умов його застосування, а саме: кут можна розуміти як упорядковану трійку точок, систему двох променів зі спільним початком, і як частину площини, обмежену цими променями.

Розглянемо найпростіше 3 наведених вище означень кута. Воно грунтується на понятті метричного простору як множини $X$ точок довільної природи. Такий простір визначається трьома аксіомами відстані між його точками: відстань між будь-якими двома різними точками простору додатна, комутативна, і не перевищує суми їх відстаней до будь-якої іншої точки множини (нерівність трикутника). Спосіб визначення відстані між точками простору називають його метрикою і позначають $\rho$. Відстань між точками $x$ i $y$ простору $X$ позначають $\rho(x, y)$, а сам простір через $(X, \rho)$. Тепер наведемо означення кута утвореного трьома точками метричного простору [3, с. 383; 10, с. 436].

Означення 1. Нехай $a, b, c$ - довільні точки метричного простору $(X, \rho)$. Упорядковану трійку $(a, b, c)$ изих точок будемо називати кутом з верииною у точиз $b$, i позначати: $\angle(a, b, c)$. Пари точок $(a, b) i(b, c)$, при цьвому, будемо називати сторонами кута.

Учням слід пояснити, що таке означення кута є логічним доповненням двох згаданих вище його означень. Тобто, у залежності від потреби, кут можна розуміти і як характеристику взаємного положення трьох точок відносно однієї з них, і як сукупність променів зі спільним початком, і як частину площини, обмежену цими променями. При цьому промені можуть утворити пряму лінію, тоді такий кут називають розгорнутим. 
Наприклад, А. Мерздяк, В. Полонський, М. Якір у підручнику з математики для 5-го класу наводять таке означення розгорнутого кута: «Кут, сторони якого утворюють пряму, називають розгорнутим» [5, с. 73].

Далі звертається увага на те, що числова характеристика кута (вимірювання кута) спирається на рівномірний поділ розгорнутого кута на 180 рівних частин. У цьому ж підручнику вводиться наступне поняття градусної міри кута: «Поділимо розгорнутий кут на 180 рівних кутів (рис. 85). Кут, утворений двома сусідніми променями, обирають за одиницю виміру. Иого величину називають градусом (від лат. gradus - «крок», «сходинка») і записують: $1^{0}$.

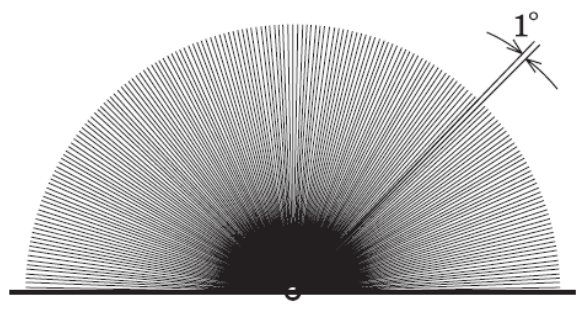

Рис. 85

Виміряти кут - це означає підрахувати, скільки одиничних кутів у ньому міститься» [5, с. 73-74].

На цій основі порівнюють кути між собою і наводять наступні визначення: «Рівні кути мають рівні градусні міри» [5, с. 74]; «Кут, градусна міра якого менша за 900, називають гострим» [5, с. 75]; «Кут, градусна міра якого більша за 90, але менша від 180, називають тупим» [5, с. 75]. А. Мерзляк, В. Полонський, М. Якір у підручнику з геометрії для 7-го класу зазначають: «Рівні кути мають рівні величини, і навпаки, якщо величини кутів рівні, то рівні й самі кути» [6, с. 27].

А. Мерздяк, Д. Номіровський, В. Полонський, М. Якір відзначають: якщо за основу вимірювання кута взяти коло, то отримуємо радіанну міру кута. Про це вони пишуть так: «Кутом в один радіан називають центральний кут кола, що спирається на дугу, довжина якого дорівнюе радіусу кола» [7, с. 81]

Виникає питання, як увести числову характеристику кута при визначенні його як упорядкованої трійки точок метричного простору. У такому випадку можна використати дише відстані між кожною з пар цих точок, пояснивши це учням на основі теореми косинусів, яка пов'язуе косинус кута трикутника 3 довжинами його сторін. Наприклад: «Квадрат сторони трикутника дорівнюе сумі квадратів двох інших сторін мінус подвоєний добуток цих сторін і косинуса кута між ними» [8, с. 20]. Отже, иогічно буде дати учням таке означення числової характеристики кута:

Означення 2. Нехай $a, b, c-$ довільні точки метричного простору $(X, \rho)$. Характеристикою кута $\angle(a, b, c)$, або кутовою характеристикою, будемо називати дійсне число $\varphi(a, b, c)$, щзо знаходиться за формулою:

$$
\varphi(a, b, c)=\frac{\rho^{2}(a, b)+\rho^{2}(b, c)-\rho^{2}(a, c)}{2 \rho(a, b) \rho(b, c)}
$$

Доцільно пояснити, що з цього означення легко отримати означення прямого кута: це кут, для якого виконується рівність $\varphi(a, b, c)=0$; означення розгорнутого кута: це кут, для якого виконується рівність $\varphi(a, b, c)=-1$; означення нульового кута: це кут, для якого виконується рівність $\varphi(a, b, c)=1$. Більше того, використовуючи Означення 2, можна дати означення прямолінійного розміщення трьох різних точок метричного простору [3, с. 384; 10, c. 436]. 
Означення 3. Будемо казати, що точки $a, b, c$ простору П розміщені прямолінійно, якще хоча б для однієї з цһих точок (наприклад, для точки b) виконуеться рівність:

$$
\varphi^{2}(a, b, c)=1 \text {. }
$$

Якщо маємо деяку множину точок, то для неї природно дати наступне означення прямолінійного розміщення [3, с. 384; 10, с. 436].

Означення 4. Будемо говорити, що множина точок метричного простору прямохінійно розміщена, якще будь-які три точки изіё множини прямолінійно розміщені.

Важливо звернути увагу учнів на те, що з рівності (1) Означення 2 можна отримати ведику кількість відомих класичних фактів, що стосуються геометрії Евкдіда [11]. Цікавим є те, що при цьому не використовуеться їх геометричний зміст. Тобто, ці результати носять дише аналітичний характер і є наслідками властивостей множини дійсних чисел. Зокрема, з рівності (1) легко отримується аналог теореми Піфагора для прямокутного трикутника [11, с. 89-90].

Теорема 1. Якщо для трьох різних точок $a, b, c$ метричного простору $(X, p)$ виконуеться рівність: $\varphi(a, b, c)=0$, то справедлива рівність:

$$
\rho^{2}(a, c)=\rho^{2}(a, b)+\rho^{2}(b, c) \text {. }
$$

Слід наголосити, що цей результат справедливий у будь-якому метричному просторі. За аналогією з геометрією Евкліда, про три точки $a, b, c$ метричного простору $(X, \rho)$, для яких виконуеться рівність: $\varphi(a, b, c)=0$, можна сказати, що вони утворюють прямокутний трикутник у цьому просторі.

Далі акцентується, що 3 рівності (2) Означення 3 можна отримати більшість результатів відносно прямолінійного розміщення точок у метричному просторі, що наведені у роботі [4]. Дійсно, якщо виконуеться рівність: $\varphi(b, a, c)=1$, то 3 рівності (1) Означення 2 отримуємо рівності:

$$
\begin{gathered}
\frac{\rho^{2}(a, b)+\rho^{2}(b, c)-\rho^{2}(a, c)}{2 \rho(a, b) \rho(b, c)}=1 ; \\
\rho^{2}(a, b)+\rho^{2}(b, c)-\rho^{2}(a, c)=2 \rho(a, b) \rho(b, c) ; \\
(\rho(a, b)-\rho(b, c))^{2}=\rho^{2}(a, c):
\end{gathered}
$$

Остання рівність рівносильна сукупності двох рівностей:

або сукупності рівностей:

$$
\left[\begin{array}{l}
\rho(a, b)-\rho(b, c)=\rho(a, c) \\
\rho(a, b)-\rho(b, c)=-\rho(a, c)
\end{array}\right.
$$

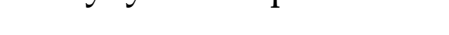

$$
\left[\begin{array}{l}
\rho(a, b)=\rho(a, c)+\rho(b, c), \\
\rho(b, c)=\rho(a, b)+\rho(a, c) .
\end{array}\right.
$$

У обох випадках точки $a, b, c$ розміщені прямолінійно у просторі $(X, \rho)$, за Означенням 3 роботи [4, с. 47].

Важливо пояснити, якщо виконуеться перша рівність сукупності, то за аналогією 3 геометрією Евкдіда можна казати, що точка с лежить між точками $a$ i $b$, або що вона $є$ внутрішньою, а точки $a$ і $b \in$ крайніми для точок $a, b, c$.

Якщо виконується друга рівність сукупності, то можна сказати, що точка $а$ лежить між точками $b$ і $c$, або що вона $є$ внутрішньою, а точки $b$ і $c \in$ крайніми для точок $a, b, c$.

Наведемо приклад, що демонструе неоднозначність поняття прямодінійності у метричному просторі. Такий приклад доречно навести в одинадцятому класі, під час вивчення визначеного інтеграла у курсі алгебри.

За відстань між двома неперервними на відрізку [0;1] функціями $f(x)$ і $g(x)$ візьмемо число $\rho(f, g)=\max _{x \in[0: 1]}\{f(x)-g(x) \mid\}$. При цьому виборі метрики множина таких функцій стає метричним простором.

Приклад 1. Розглянемо чотири лінійних функції: $y_{1}=x, y_{2}=-x, y_{3}=x+1, y_{4}=x-2$.

Для зручності введемо позначення: $\rho\left(y_{i}, y_{j}\right)=\rho_{i j}$ i $\varphi\left(y_{i}, y_{j}, y_{k}\right)=\varphi_{i j k}(i, j, k=1,2,3,4)$. 
Знайдемо відстані між функціями $y_{1}, y_{2}, y_{3}, y_{4}$ за вказаною вище метрикою. Будемо мати:

$\rho_{1_{2}}=2 ; \rho_{1_{3}}=1 ; \rho_{1_{4}}=2 ; \rho_{2_{3}}=3 ; \rho_{2_{4}}=4 ; \rho_{3_{4}}=3$.

3 отриманих рівностей постає, що точки $y_{1}, y_{2}, y_{3}$ розміщені прямолінійно, причому точка $y_{1}$ лежить між точками $y_{2}, y_{3}$. Крім того, точки $y_{1}, y_{2}, y_{4}$ теж розміщені прямолінійно і точка $y_{1}$ лежить також між точками $y_{3}, y_{4}$. Оскільки серед обох трійок точок є дві спільні: $y_{1}$ i $y_{3}$, то у геометрії Евкліда усі чотири точки $y_{1}, y_{2}, y_{3}, y_{4}$ повинні бути прямодінійно розміщені. Однак, точки $y_{1}, y_{2}, y_{4}$ розташовані на однаковій відстані одна від одної (утворюють рівносторонній трикутник). Цей факт демонструе неоднозначність прямолінійного розміщення точок у метричному просторі.

Якщо за відстань між двома неперервними на відрізку [0;1] функціями $f(x)$ i $g(x)$ взяти число $\rho(f, g)=\int_{0}^{1}|f(x)-g(x)| d x$, то множина таких функцій стає метричним простором. Фактично, ця відстань чисельно дорівнює площі фігури, що обмежена графіками функцій $f(x)$ і $g(x)$ на відрізку [0;1].

Приклад 2. Розгдянемо функції $y_{1}, y_{2}, y_{3}, y_{4} 3$ Прикладу 1. Знайдемо відстані між функціями $y_{1}, y_{2}, y_{3}, y_{4}$ за вказаною вище метрикою. Будемо мати:

$$
\rho_{1_{2}}=1 ; \rho_{1_{3}}=1 ; \rho_{1_{4}}=2 ; \rho_{2_{3}}=2 ; \rho_{2_{4}}=1 ; \rho_{3_{4}}=3 \text {. }
$$

Тепер, використовуючи формулу (1), обчислимо усі мождиві кутові характеристики для цих функцій:

$$
\begin{aligned}
& \varphi_{21_{3}}=-1 ; \varphi_{21_{4}}=1 ; \varphi_{31_{4}}=-1 ; \varphi_{12_{3}}=1 ; \varphi_{12_{4}}=-1 ; \varphi_{32_{4}}=-1 ; \\
& \varphi_{13_{2}}=1 ; \varphi_{13_{4}}=1 ; \varphi_{23_{4}}=1 ; \varphi_{14_{2}}=1 ; \varphi_{14_{3}}=1 ; \varphi_{24_{3}}=1 .
\end{aligned}
$$

Оскільки ці значення задовольняють рівність (2), то, у відповідності до Означення 3 і Означення 4, усі чотири функції розміщені прямолінійно у вибраному просторі. 3 отриманих рівностей випливає також, що ці функції розміщені у такому порядку: $y_{3}, y_{1}$, $y_{2}, y_{4}$.

Приклади 1 і 2 демонструють зміну геометрії простору при зміні його метрики.

Висновки. Наведений вище матеріал свідчить про можливість засвоєння основних понять неевклідових геометрій учнями, які навчаються у класах 3 поглибленим вивченням математики. На базовому рівні ці поняття можуть засвоюватись інтуїтивно, з використанням їх опису, характеристики основних властивостей та наведенням відповідних прикладів. На профільному рівні можна вводити аксіоматику відстані між точками метричного простору, приклади метричних просторів та відповідні числові характеристики основних геометричних понять.

У подальшому науковому пошуку доцільно продовжити дослідження найбільш ефективних шляхів опанування учнями шкільного курсу математики, зокрема щодо вивчення властивостей плоского розміщення точок, використавши при цьому означення кута, утвореного трьома точками метричного простору.

\section{Список використаних джерел:}

1. Бурова Н. А. Изучение раздичных типов неевкдидовых геометрий как фактор формирования профессионализма учителя математики. Педагогический профессионализм в образовании: Сборник научных трудов XIII Международной научн.-практ. конф., г. Новосибирск, 15-16 февр. 2018. Новосибирск, 2018. С. 95-98.

2. Гильберт Д. Основания геометрии / пер. с нем. под ред. А. В. Васильев. Петроград: Сеятель, 1923. $152 \mathrm{c}$.

3. Кузьмич В. І. Геометричні властивості метричних просторів. Український математичний журнал. 2019. № 3 (71). С. 382-399. 
4. Кузьмич В. І. Формування в школярів понять відстані та прямолінійності засобами метричної геометрії. Педагогічний альманах: збірник наукових праць / редкол. В. В. Кузьменко (голова) та ін. Херсон: КВНЗ «Херсонська академія неперервної освіти», 2019. Випуск 42. С. 43-50.

5. Мерзляк А. Г., Полонський В. Б., Якір М. С. Математика. 5 клас : підруч. для закладів загальної середньої освіти. Харків: Гімназія, 2018. 272 с.

6. Мерзляк А. Г., Полонський В. Б., Якір М. С. Геометрія. Пропедевтика поглибленого вивчення : навч. посіб. для 7 кл. $з$ поглибленим вивченням математики. Харків: Гімназія, 2015. 192 с.

7. Мерзляк А. Г., Номіровський Д. А., Полонський В. Б., Якір М. С. Алгебра і початки аналізу : початок вивчення на поглиб. рівні 38 кл., проф. рівень : підруч. для 10 кл. закладів загальної середньої освіти. Харків: Гімназія, 2018. 512 с.

8. Мерзляк А. Г., Полонський В. Б., Якір М.С. Геометрія для загальноосвітніх навчальних закладів з поглибленим вивченням математики : підруч. для 9 кл. загальноосвіт. навч. закладів. Х. : Гімназія, 2017. 304 с.

9. Начала Евкдида. Книги I-VI. / пер. с греч. и коммент. Д. Д. Мордухай-Бодтовский. М.-Д.: Гостехиздат, 1948. 447 с.

10. Kuz'mich V. I. Geometric properties of metric spaces. Ukrainian Mathematical Journal. 2019. Vol. 71, No. 3. P. 435-454.

11. Kuz'mich V. I., Savchenko A. G. Geometric relations in an arbitrary metric space. Математичні Cmydii. 2019. № 1 (52). C. 86-95.

12. Lenart I. The Algebra of Projective Spheres on Plane, Sphere and Hemisphere. Journal of Applied Mathematics and Physics. 2020. Vol. 8, No. 10. P. 2286-2333.

13. Lénárt I., Rybak A. Comparative Geometry in Primary and Secondary School. The Pedagogy of Mathematics: Is There a Unifying Logic? Johannesburg: Mapungubwe Institute for Strategic Reflection (MISTRA), 2017. 274 c.

\section{References:}

1. Burova, N. A. (2018). Izucheniye razlichnykh tipov neyevklidovykh geometriy kak faktor formirovaniya professionalizma uchitelya matematiki [Study of various types of non-Euclidean geometries as a factor in the formation of a mathematics teacher's professionalism], Pedagogicheskiy professionalizm $v$ obrazovanii, sbornik nauchnykh trudov XIII Mezhdunarodnoy nauchnoprakticheskoy konferentsii [Pedagogical professionalism in education, Proceedings of the XIII International Scientific-Practical Conference]. Novosibirsk [in Russian].

2. Gilbert, D. (1923). Osnovaniia geometrii [Geometry bases]. (A. V. Vasilev, Trans.). Petrograd: Seiatel [in Russian].

3. Kuz'mich, V.I. (2019). Heometrychni vlastyvosti metrychnykh prostoriv [Geometric properties of metric spaces]. Ukrainskyi matematychnyi zhurnal, 3(71), 382-399 [in Ukrainian].

4. Kuz'mich, V. I. (2019). Formuvannia v shkoliariv poniat vidstani ta priamoliniinosti zasobamy metrychnoi heometrii [Formation of pupils concepts of distance and straightness by means of metric geometry]. Pedahohichnyi almanakh, 42, 43-50 [in Ukrainian].

5. Merzliak, A. G., Polonskyi, V. B., \& Yakir, M. S. (2018). Matematyka. 5 klas: pidruch. dlia zakladiv zahalnoi serednoi osvity [Mathematics. The fifth grade: a textbook for general secondary education institutions]. Kharkiv: Himnaziia [in Ukrainian].

6. Merzliak, A. G., Polonskyi, V. B., \& Yakir, M. S. (2015). Propedevtyka pohlyblenoho vyvchennia: navch. posib. dlia $7 \mathrm{kl}$. z pohlyblenym vyvchenniam matematyky [Geometry. Propaedeutics of in-depth study: a textbook for the seventh grade with in-depth study of mathematics]. Kharkiv: Himnaziia [in Ukrainian].

7. Merzliak, A. G., Nomirovskyi, D. A., Polonskyi, V. B., \& Yakir, M. S. (2018). Alhebra $i$ pochatky analizu: pochatok vyvchennia na pohlyb. rivni z $8 \mathrm{kl}$., prof. riven: pidruch. dlia $10 \mathrm{kl}$. zakladiv zahalnoi serednoi osvity [Algebra and the beginnings of analysis: the beginning of in-depth study from the eighth grade, a professional level: a textbook for the tenth grade of general secondary education]. Kharkiv: Himnaziia [in Ukrainian].

8. Merzliak, A. G., Polonskyi, V. B., \& Yakir, M. S. (2017). Heometriia dlia zahalnoosvitnikh navchalnykh zakladiv z pohlyblenym vyvchenniam matematyky: pidruchnyk dlia 9 klasiv zahalnoosvitnikh navchalnykh zakladiv [Geometry for comprehensive educational institutions with in-depth study of mathematics: a textbook for the 9th grade of comprehensive educational institutions]. Kharkiv: Himnaziia [in Ukrainian]. 
9. Mordukhai-Boltovskii, D. D. (Ed.) (1948). Nachala Evklida. Knigi I-VI [The beginnings of Euclid. Books I-VI]. (D. D. Mordukhay-Boltovskiy, Trans.). Moscow-Leningrad: Gostekhizdat [in Russian].

10. Kuz'mich, V. I. (2019). Geometric properties of metric spaces. Ukrainian Mathematical Journal, 3 (71), 435-454. doi: 10.1007/s11253-019-01656-1 [in English].

11. Kuz'mich, V. I., \& Savchenko, A. G. (2019). Geometric relations in an arbitrary metric space. Matematychni Studii, 1(52), 86-95. doi: 10.30970/ms.52.1.76-85 [in English].

12. Lenart, I. (2020). The Algebra of Projective Spheres on Plane, Sphere and Hemisphere. Journal of Applied Mathematics and Physics, 10(8), 2286-2333. doi: 10.4236/jamp.2020.810171 [in English].

13. Lénárt, I., \& Rybak, A. (2017). Comparative Geometry in Primary and Secondary School. In: The Pedagogy of Mathematics: Is There a Unifying Logic? (pp. 107-124). Johannesburg: Mapungubwe Institute for Strategic Reflection (MISTRA) [in English].

Kuz'mich V. I., orcid.org/0000-0002-8150-3456

Kuzmich L. V.,

FORMATION OF THE CONCEPT OF AN ANGLE IN THE SCHOOL orcid.org/0000-0002-6727-9064 COURSE OF MATHEMATICS BY MEANS OF METRIC GEOMETRY

In the school mathematics course, the corner is systematically studied from the fifth grade. Surprisingly, this concept still has no fixed definition, or at least no description. Even in higher mathematics, it is interpreted differently, not to mention school textbooks. The angle is perceived both as a line and as part of a plane, and sometimes the angle is identified with its numerical characteristic. This perception of the angle, in our opinion, is due to its widespread use in various fields of science and technology.

This paper proposes the definition of an angle as an ordered triple of points. This definition, in our opinion, is a logical addition to the existing definitions of angle. In addition, this approach to the concept of angle makes it possible to use elements of metric geometry to study its properties, as well as to use the angle to define the concept of rectilinear placement of points. The application of the basic concepts of metric geometry to the study of the properties of angle makes it possible to acquaint pupils with the elements of non-Euclidean geometry, which is currently completely absent in school textbooks on geometry, including textbooks for classes with depth study of mathematics.

The introduction of the generalized concept of angle in the school course of geometry, in our opinion, should begin with a demonstration of examples that indicate the relativity of basic geometric concepts - point, straightness, distance, angle. Such examples will prepare students for the adequate perception in the future of the basic concepts and relations of non-Euclidean geometries. The use of metric geometry for this eliminates the need to consider a significant number of axioms, because it uses only three axioms of distance, which are intuitive to students.

The paper presents a number of examples that can be considered in lessons in classes with advanced study of mathematics, as well as in extracurricular activities in mathematics classes, or in electives in mathematics.

Key words: advanced study of mathematics, point, angle, distance, space, metric, metric geometry, non-Euclidean geometry.

Дата надходження статті: 29.10.2020 p. Рецензент: доктор педагогічних наук, професор Кузьменков С. Г. 